\title{
Individualized electronic decision support and reminders to improve diabetes care in the community: COMPETE II randomized trial
}

\author{
Anne Holbrook MD PharmD, Lehana Thabane PhD, Karim Keshavjee MD MBA, \\ Lisa Dolovich PharmD MSc, Bob Bernstein PhD MDCM, David Chan MD MSc, Sue Troyan, \\ Gary Foster PhD, Hertzel Gerstein MD MSc, for the COMPETE II Investigators
}

$\infty \quad$ See related commentary by Grant and Middleton, page 17

\section{ABSTRACT}

Background: Diabetes mellitus is a complex disease with serious complications. Electronic decision support, providing information that is shared and discussed by both patient and physician, encourages timely interventions and may improve the management of this chronic disease. However, it has rarely been tested in community-based primary care.

Methods: In this pragmatic randomized trial, we randomly assigned adult primary care patients with type 2 diabetes to receive the intervention or usual care. The intervention involved shared access by the primary care provider and the patient to a Web-based, colour-coded diabetes tracker, which provided sequential monitoring values for 13 diabetes risk factors, their respective targets and brief, prioritized messages of advice. The primary outcome measure was a process composite score. Secondary outcomes included clinical composite scores, quality of life, continuity of care and usability. The outcome assessors were blinded to each patient's intervention status.

Results: We recruited sequentially 46 primary care providers and then 511 of their patients (mean age 60.7 [standard deviation 12.5] years). Mean follow-up was 5.9 months. The process composite score was significantly better for patients in the intervention group than for control patients (difference 1.27, 95\% confidence interval [Cl] 0.79$1.75, p<0.001) ; 61.7 \%(156 / 253)$ of patients in the intervention group, compared with $42.6 \%$ (110/258) of control patients, showed improvement (difference 19.1\%, $p<$ 0.001). The clinical composite score also had significantly more variables with improvement for the intervention group $(0.59,95 \% \mathrm{Cl} 0.09-1.10, p=0.02)$, including significantly greater declines in blood pressure $(-3.95 \mathrm{~mm} \mathrm{Hg}$ systolic and $-2.38 \mathrm{~mm} \mathrm{Hg}$ diastolic) and glycated hemoglobin $(-0.2 \%)$. Patients in the intervention group reported greater satisfaction with their diabetes care.

Interpretation: A shared electronic decision-support system to support the primary care of diabetes improved the process of care and some clinical markers of the quality of diabetes care. (ClinicalTrials.gov trial register no. NCT00813085.)

Une version française de ce résumé est disponible à l'adresse www.cmaj.ca/cgi/content/full/cmaj.081272/DC1

CMAJ 2009;181(1-2):37-44
$\mathrm{D}$ iabetes mellitus affects about $7 \%$ of the populations of Canada and the United States - some 23 million people - and accounts for direct annual health care costs of about $\$ 105$ billion. ${ }^{1,2}$ At least $90 \%$ of people with diabetes have type 2 diabetes. In addition to being a major risk factor for cardiovascular disease (whereby the risks of myocardial infarction and stroke are 2-4 times those in the nondiabetic population), diabetes is the primary cause of renal failure, blindness and nontraumatic limb amputation. ${ }^{1,2}$ International guidelines recommend interventions to prevent these complications, mainly on the basis of evidence from large randomized clinical trials. $^{3-7}$ These interventions include control of glucose, blood pressure and lipids; vascular protection with acetylsalicylic acid; diet; exercise; renal protection; smoking cessation for smokers; prevention and treatment of retinopathy; and education about foot surveillance. In a recent study, intensive intervention to address multiple risk factors was associated with lower rates of mortality (by 56\%), cardiovascular events (by 59\%), nephropathy (by 56\%) and retinopathy (by 55\%) over 13 years relative to conventional therapy. ${ }^{8}$ These major changes in the frequency of events occurred despite the small differences $(0.3 \%$ for glycated hemoglobin, $6 \mathrm{~mm} \mathrm{Hg}$ for systolic blood pressure and 0.2 $\mathrm{mmol} / \mathrm{L}$ for low-density lipoprotein [LDL] cholesterol) between groups by the end of the open follow-up period. However, optimal care of patients with diabetes in the community has been difficult to achieve, because it can be difficult to sustain regular monitoring and attention to many risk factors over many years, especially for patients with multiple health care providers., ${ }^{90}$

Most diabetes care takes place in the community, largely managed in the primary care setting. In this environment, short visits, competing visit objectives, lack of proactive systems for disease surveillance and alerting support, difficulties staying up to date on ever-shifting targets, challenges associated with managing multiple medications and inertia related to chronic disease (on the part of both patient and physician)

From the Division of Clinical Pharmacology and Therapeutics (Holbrook), the Department of Clinical Epidemiology and Biostatistics (Thabane, Troyan, Foster), the Department of Family Medicine (Dolovich, Chan) and the Department of Medicine (Gerstein), McMaster University, Hamilton, Ont; InfoClin (Keshavjee), Toronto, Ont.; and the Department of Family Medicine (Bernstein), University of Toronto, Toronto, Ont. The list of COMPETE II Investigators appears in Appendix 5 (available at www.cmaj.ca/cgi/content/full/cmaj.081272/DC2). 
are all potential barriers to aggressive management. Efforts to improve patients' self-management are thought to be central to improving diabetes management. ${ }^{11-13}$ The most innovative and effective self-management interventions may be those that target the main provider and the patient as a unit, ideally producing a motivated patient who is willing to take charge of his or her care, with the primary care provider as a resource coach and triage to consultation services as needed. ${ }^{14-18}$

All major Western health care systems are now advocating the expanded use of electronic medical records to improve the legibility, portability and storage of records and to improve the quality and cost-effectiveness of patient care. ${ }^{19,20}$ However, electronic medical records typically provide little decision support for patient management. Computerized decision-support systems integrated with the electronic medical record may improve prescribing and quality of care through the provision of patient-specific summaries and recommendations that are seamlessly integrated into the practice workflow. ${ }^{14,21,22}$ The limited amount of high-quality research available suggests that computerized decision-support systems can change provider behaviour. However, there have been too few randomized trials to confirm that they can reliably improve patient outcomes. ${ }^{23}$ Given the major expense of electronic medical records and computerized decision support, the effectiveness and cost-effectiveness of such systems is a major information gap.

Because of the high prevalence of diabetes, its significant morbidity and the multiple targets for therapy, both patients and providers are likely to benefit from an advanced, diabetesspecific computerized decision-support system. Our objective was to rigorously evaluate whether such a system, shared between patient and primary care provider, could improve the quality of diabetes management in primary care. The specific hypothesis was that patients in the intervention group, who had electronic and paper access to an individual diabetes tracker (with data related to recent monitoring and results and targets for 13 risk factors) and whose information was shared with their primary care providers, would have improved quality of diabetes care.

\section{Methods}

\section{Participants and procedures}

The Computerization of Medical Practices for the Enhancement of Therapeutic Effectiveness (COMPETE) II study was a pragmatic randomized trial of a complex intervention that was conducted in the province of Ontario, Canada, from late 2002 to the end of 2003. It was approved by the 3 presiding research ethics boards: St. Joseph's Healthcare, Hamilton; the Sisters of Charity, Ottawa; and Group Health Centre - Sault Area Hospital, Sault Ste. Marie.

We recruited community-based primary care providers across Ontario who were already using electronic medical records in their practices. Once the providers had signed consent, they identified from their rosters patients 18 years or older with a diagnosis of type 2 diabetes who were fluent in English and were able to understand the study description. From this list, we randomly selected the patients who would be approached for recruitment, and the providers sent invitations to their respective patients by mail. The randomization process used allocation concealment and central computer generation of group assignment, and it was stratified by provider and in blocks of 6. Participating patients and primary care providers then completed baseline questionnaires. We instructed patients in the intervention group to visit their respective local laboratories for a predetermined set of relevant blood tests and then to make an appointment with their respective family physicians for a week later. Study follow-up was to be 6 months.

Table 1: Variables recorded in diabetes tracker and composite scoring

\begin{tabular}{|c|c|c|c|c|}
\hline Tracker variable & Process target & $\begin{array}{l}\text { Maximum score } \\
\text { per period* }\end{array}$ & Clinical target & $\begin{array}{l}\text { Maximum score } \\
\text { per periodt }\end{array}$ \\
\hline Blood pressure & Quarterly & 2 & $<130 / 80 \mathrm{~mm} \mathrm{Hg}$ & 1 \\
\hline Cholesterol & Semiannual & 1 & $\mathrm{LDL}<2.6 \mathrm{mmol} / \mathrm{L}$ & 1 \\
\hline Glycated hemoglobin & Semiannual & 1 & $<0.07 \%$ & 1 \\
\hline Foot check & Semiannual & 1 & $\begin{array}{l}\text { No foot ulcers or } \\
\text { neuropathy }\end{array}$ & 1 \\
\hline Kidney & Semiannual to annual & 1 & No microalbuminuria & 1 \\
\hline Weight & Quarterly & 2 & $\mathrm{BMI}<27$ & 1 \\
\hline Physical activity & Quarterlył & 1 & At least $210 \mathrm{~min} / \mathrm{wk}$ & 1 \\
\hline Smoking & Quarterly, if smoking $\ddagger$ & 1 & Nonsmoker & 1 \\
\hline Eye check & Annual & Not used for composite & No retinopathy & Not used for composite \\
\hline $\begin{array}{l}\text { Acetylsalicylic acid or } \\
\text { equivalent }\end{array}$ & Semiannual & Not used for composite & $80-325 \mathrm{mg} / \mathrm{d}$ & Not used for composite \\
\hline ACE inhibitors & Semiannual & Not used for composite & $\begin{array}{l}\text { Taking an ACE inhibitor } \\
\text { or ARB }\end{array}$ & Not used for composite \\
\hline Flu shot & Annual & Not used for composite & Annual dose in the fall & Not used for composite \\
\hline
\end{tabular}

Note: $A C E$ = angiotensin-converting enzyme, $A R B=$ angiotensin-receptor blocker, $B M I$ = body mass index, LDL = low-density lipoprotein .

* Maximum total score for process composite $=10$ ( 8 variables).

†Maximum total score for clinical target composite $=8$ ( 8 variables).

‡Recommended target was quarterly, but data were available once before and after intervention. 


\section{Intervention}

The cornerstone of the intervention was the Web-based diabetes tracker of the Computerization of Medical Practices for the Enhancement of Therapeutic Effectiveness study II (for screen views, see Appendixes 1 and 2, available at www .cmaj.ca/cgi/content/full/cmaj.081272/DC2). The clinical subcommittee for the study chose 13 variables related to quality of diabetes care; these variables were based on guidelines of the Canadian Diabetes Association, ${ }^{2}$ updated statements of the American Diabetes Association ${ }^{24}$ and an internal literature review. For each variable, we set targets for the monitoring process and for the clinical outcome (Table 1). Details on the key features of the diabetes tracker are presented in Appendix 3 (available at www.cmaj.ca/cgi/content /full/cmaj.081272/DC2).

The electronic tracker interfaced with the provider's electronic medical record ${ }^{25}$ and with an automated telephone reminder system for the patient. In addition to giving patients Web-based access to the tracker, we mailed a colour-coded tracker page to each patient in the intervention group (4 times a year) and asked that this page be taken to physician appointments. For the telephone reminder system, intervention patients registered with a voice biometric and then received monthly reminders for medications and for laboratory and physician visits. The overall intent of the intervention was to re-engineer the flow of care, such that updated tracker information and the most recent laboratory results were available to both provider and patient at the time of the patient's visit. Patients in the control group continued receiving usual care from their respective primary care providers.

\section{Outcome measures}

The primary outcome measure was based on improvement of process. We calculated this outcome as the difference between the intervention and control groups in terms of mean change for individual patients in a composite score of process quality for 6 months after randomization relative to baseline. The process composite score represented the sum of the quality of monitoring of each of the relevant variables (glycated hemoglobin, blood pressure, LDL cholesterol, body mass index [BMI], albuminuria, foot check, smoking and physical activity) compared with their respective targets (see Table 1). We modelled these recommendations on the guidelines of the Canadian Diabetes Association ${ }^{7}$ and the American Diabetes Association. ${ }^{24}$ If we could not find any evidence of a process (e.g., checking feet), we assumed that it had not happened. Secondary outcomes included the 8-item composite for clinical marker outcomes (Table 1), a subset designated as the "ABC composite" (" $\mathrm{A}_{1 \mathrm{C}}$ " or glycated hemoglobin, blood pressure and cholesterol [LDL]), evaluations of the tracker system and its effect on perceived usefulness, continuity of care ${ }^{26}$ and quality of life (using the SF-12 questionnaire $^{27}$ for general quality of life and the Diabetes39 questionnaire ${ }^{28,29}$ for diabetes-related quality of life). Both process and clinical composites were evaluated "harshly," such that worsening of a variable counted against improvements in other variables. We collected most of the data for the primary outcome by chart review, with other outcomes reflecting a combination of chart review and telephone questionnaires. Participants' views on the automated telephone reminder system ${ }^{30}$ and data on the estimated cost-effectiveness of the intervention have been published elsewhere or are in preparation for publication in separate manuscripts.

\section{Data analysis}

Statisticians blinded to treatment allocation performed the data analysis. We accounted for all patients who underwent randomization in the groups to which they were assigned (i.e., intention-to-treat analysis). The null hypothesis was that the

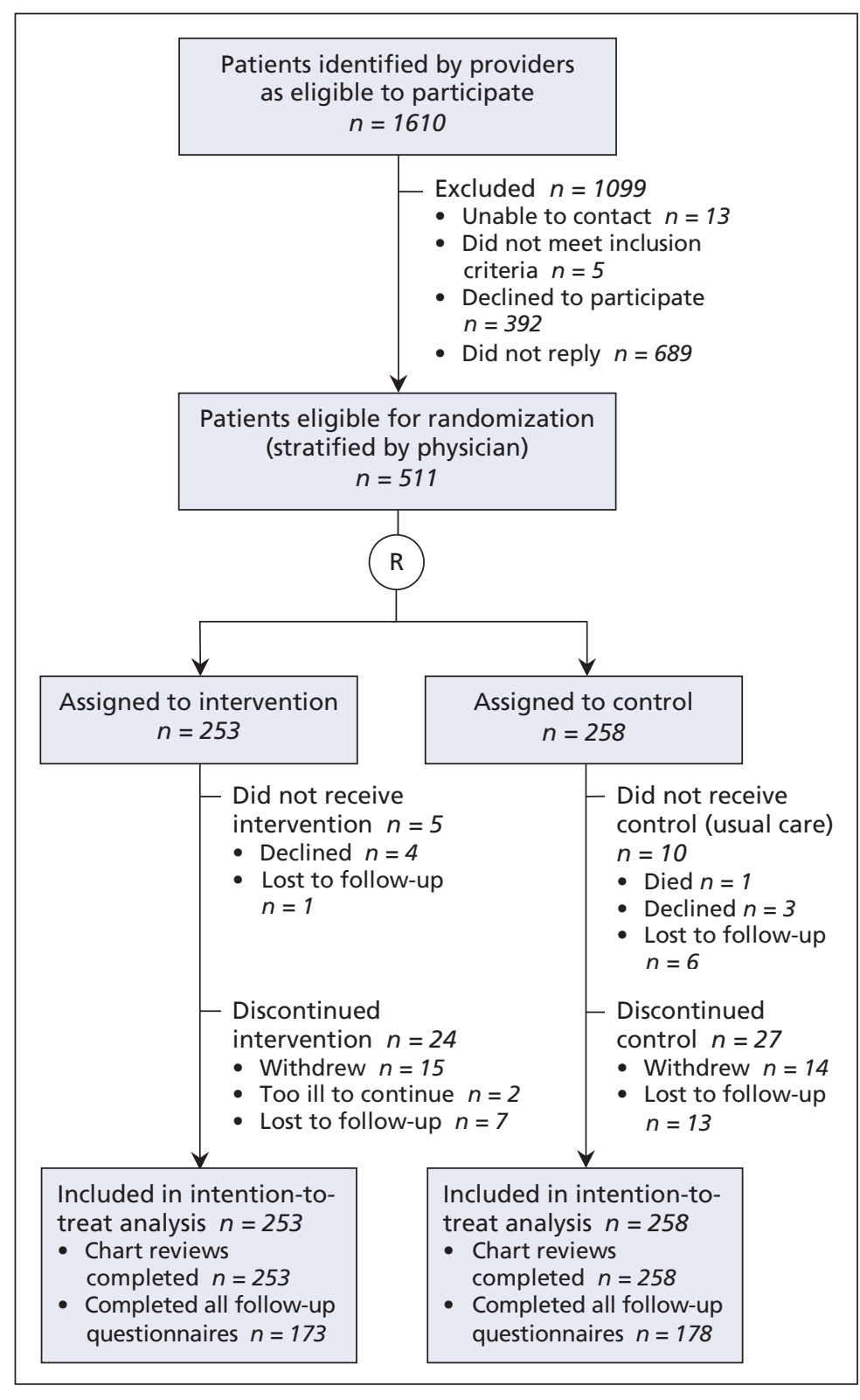

Figure 1: Flow diagram for the Computerization of Medical Practices for the Enhancement of Therapeutic Effectiveness II (COMPETE II) study. $R=$ randomization. 
Table 2: Baseline characteristics of participants

\begin{tabular}{|c|c|c|c|}
\hline \multirow[b]{2}{*}{ Characteristic } & \multicolumn{3}{|c|}{ No. $(\%)$ of participants* } \\
\hline & $\begin{array}{l}\text { Intervention } \\
n=253\end{array}$ & $\begin{array}{l}\text { Control } \\
n=258\end{array}$ & $\begin{array}{l}\text { Total } \\
n=511\end{array}$ \\
\hline Sex & $130(51.4)$ & $122(47.3)$ & $252(49.3)$ \\
\hline Age, yr, mean (SD) & $61.0(13.1)$ & $60.5(11.9)$ & $60.7(12.5)$ \\
\hline \multicolumn{4}{|l|}{ Education level } \\
\hline Elementary school only & $52(20.6)$ & $58(22.5)$ & $110(21.5)$ \\
\hline Secondary school only & $120(47.4)$ & $106(41.1)$ & $226(44.2)$ \\
\hline College or university & $61(24.1)$ & $69(26.7)$ & $130(25.4)$ \\
\hline Postgraduate school & $15 \quad(5.9)$ & $16 \quad(6.2)$ & $31 \quad(6.1)$ \\
\hline Unknown & $5 \quad(2.0)$ & $9 \quad(3.5)$ & $14 \quad(2.7)$ \\
\hline \multicolumn{4}{|l|}{ Living situation } \\
\hline Alone & $45(17.8)$ & $51(19.8)$ & $96(18.8)$ \\
\hline With family & $200(79.1)$ & $198(76.7)$ & $398(77.9)$ \\
\hline With friends & $2(0.8)$ & $0 \quad(0.0)$ & $2(0.4)$ \\
\hline Unknown & $6 \quad(2.4)$ & $9 \quad(3.5)$ & $15 \quad(2.9)$ \\
\hline \multicolumn{4}{|l|}{ Computer use } \\
\hline Never & $109(43.1)$ & $123(47.7)$ & $232(45.4)$ \\
\hline Monthly & $8 \quad(3.2)$ & 10 & 18 (3.5) \\
\hline Weekly & 30 (11.9) & $25 \quad(9.7)$ & $55(10.8)$ \\
\hline Daily & $101(39.9)$ & $91(35.3)$ & $192(37.6)$ \\
\hline Unknown & $5 \quad(2.0)$ & $9 \quad(3.5)$ & $14 \quad(2.7)$ \\
\hline \multicolumn{4}{|l|}{ Internet use } \\
\hline Never & $130(51.4)$ & $139(53.9)$ & $269(52.6)$ \\
\hline Monthly & $12(4.7)$ & $19 \quad(7.4)$ & $31 \quad(6.1)$ \\
\hline Weekly & $34(13.4)$ & $25 \quad(9.7)$ & $59(11.5)$ \\
\hline Daily & $72(28.5)$ & $65(25.2)$ & $137(26.8)$ \\
\hline Unknown & $5 \quad(2.0)$ & $10 \quad(3.9)$ & $15 \quad(2.9)$ \\
\hline $\begin{array}{l}\text { Time since diabetes } \\
\text { diagnosis, yr, mean (SD) }\end{array}$ & $8.7 \quad(9.0)$ & $10.0(10.7)$ & $9.3 \quad(9.9)$ \\
\hline \multicolumn{4}{|l|}{ Medications } \\
\hline Metformin & $136(53.8)$ & $136(52.7)$ & $272(53.2)$ \\
\hline Glyburide & $62(24.5)$ & $63(24.4)$ & $125(24.5)$ \\
\hline $\begin{array}{l}\text { Other oral hypoglycemic } \\
\text { drugs }\end{array}$ & $36(14.2)$ & $31(12.0)$ & $67(13.1)$ \\
\hline Insulin & $39(15.4)$ & $47(18.2)$ & $86(16.8)$ \\
\hline \multicolumn{4}{|l|}{ Diabetes complications } \\
\hline Myocardial infarction & $34(13.4)$ & $36(14.0)$ & $70(13.7)$ \\
\hline Stroke & $14 \quad(5.5)$ & $16 \quad(6.2)$ & $30 \quad(5.9)$ \\
\hline Peripheral vascular disease & $48(19.0)$ & $37(14.3)$ & $85(16.6)$ \\
\hline Renal disease & $18(7.1)$ & $19 \quad(7.4)$ & $37 \quad(7.2)$ \\
\hline \multicolumn{4}{|l|}{ Diabetes management $\dagger$} \\
\hline Primary care provider $¥$ & $221(87.4)$ & $219(84.9)$ & $440(86.1)$ \\
\hline Other providers involved§ & $106(41.9)$ & $101(39.1)$ & $207(40.5)$ \\
\hline
\end{tabular}

Note: $\mathrm{SD}=$ standard deviation

*Unless indicated otherwise.

†Visit to provider for diabetes care in the 6 months before randomization.

¥A total of 432 patients had visited their family physician, and 8 had visited a nurse practitioner.

§Includes medical specialists (e.g., internist, endocrinologist, ophthalmologist, nephrologist)

optometrist, chiropodist, nutritionist and others who provide care related to diabetes. mean improvements in the process-ofcare score for the 2 populations (intervention and control) would be equal. Based on $\alpha=0.05$ and a 2 -tailed test with 1:1 allocation, the study had $80 \%$ power to detect a minimal clinically important difference of 1 , with a total sample of 284. The sample size was calculated using Power and Precision software (www.power-analysis.com). The unit of randomization was the patient, because patients were considered the main determinant of intervention success. We then adjusted the sample size for potential clustering of scores within a provider's practice, assuming an intraclass correlation of 0.08 based on preliminary results for a few practices. The required sample was 508 patients ( 254 per group).

We imputed missing data using multiple imputation methods. ${ }^{31}$ We used $t$ tests to assess the difference between groups in terms of change in the process composite score. We used the $\chi^{2}$ statistic to assess the proportions of patients for whom the composite improved or worsened. We analyzed clinical outcomes in 2 ways: whether there was any change (scoring each variable that improved as +1 , each variable that worsened as -1 and each variable with no change as 0 ) and whether the outcomes met the targets (which was more challenging). We report the results as estimates of effect, with corresponding $95 \%$ confidence intervals (CIs) and associated $p$ values. Analyses using generalized estimating equations to adjust for any clustering by provider did not change the results. We did not specify the operational definitions of success for the composite outcomes in the study protocol, but we finalized these definitions before undertaking the data analysis. A study graph displaying the intervention components and outcome assessments is available in Appendix 4 (available at www.cmaj.ca /cgi/content/full/cmaj.081272/DC2). ${ }^{32}$

\section{Role of funding source}

The funding source was not involved in the study design, implementation, analysis or manuscript writing, which were solely managed by the investigators.

\section{Results}

We recruited 46 providers (mean age 
45.2 [standard deviation, SD, 10.0] years, 17 [37\%] women), of whom 43 were physicians and 3 were nurse practitioners. These providers were using a total of 5 different types of electronic medical records. A total of 1610 patients randomly selected from the rosters of these providers met the study criteria, of whom 511 patients (mean age 60.7 [SD 12.5] years, 252 [49.3\%] women, 336 [65.8\%] completed high school) agreed to participate, provided signed consent and were randomly assigned to the intervention or control group (Figure 1). Mean follow-up was 5.9 months (median 6.3 [SD 1.3]). The median time since diagnosis of diabetes was 5.9 (interquartile range 10.2 ) years; 86 patients $(16.8 \%)$ were taking insulin (Table 2).

\section{Process composite score}

At baseline, the process composite score for both groups was 5.19 (Table 3), which indicates that there was evidence of monitoring in the previous 6 months for about half of the specified risk factors. Despite technical challenges, the primary outcome of process composite score for checks of glycated hemoglobin, blood pressure, LDL cholesterol, albuminuria, BMI, foot surveillance, exercise and smoking improved significantly more in the intervention group than in the control group (1.33 v. 0.06; difference $1.27,95 \%$ CI 0.79 to $1.75, p<0.001$ ). One hundred and fifty-six $(61.7 \%)$ of the patients in the intervention group, compared with $110(42.6 \%)$ in the control group, had an improvement in their process composite score, (difference $19.1 \%$, $p<0.001)$. Notably, $88(34.8 \%)$ of the intervention patients and $46(17.8 \%)$ of the control patients had an improvement of at least 3 points on the score. Number of visits to the primary care provider (as recommended) increased significantly more in the intervention group than in the control group (difference of 0.66 , $95 \%$ CI 0.37 to 1.02 . $p<0.001)$.

\section{Clinical outcomes}

At baseline, certain individual risk factors were reasonably well controlled: glycated hemoglobin about 7\%, mean blood pressure about $135 / 75 \mathrm{~mm} \mathrm{Hg}$ and LDL cholesterol about $2.5 \mathrm{mmol} / \mathrm{L}$ (Table 4). However, only 19 (7.5\%) of the patients in the intervention group had all 3 of these risk factors on target. There was a statistically significant difference in the 2 "clinical improvement" composite scores (i.e., the 8-variable composite score and the 3-variable "ABC" composite score). The intervention group had a better change score than the control group for both the 8-variable composite (difference 0.55, $95 \%$ CI 0.04 to $1.07, p=0.036)$ and the ABC composite $(0.34$, $95 \%$ CI 0.04 to $0.65, p=0.028)$. The intervention group had improvement in the number of clinical composite variables that were on target (mean difference 0.16 relative to the control group); however, this difference was not statistically significant $(p=0.26)$. In the analysis of the ABC composite, the intervention group had a greater mean increase in the number of variables on target $(0.19,95 \%$ CI 0.004 to $0.38, p=0.049)$. There were also statistically significant improvements in actual blood

Table 3: Results for process-related outcomes

\begin{tabular}{|c|c|c|c|c|c|}
\hline \multirow[b]{3}{*}{ Outcome } & \multicolumn{4}{|c|}{ Study group; timeframe; mean score (SD)* } & \multirow{3}{*}{$\begin{array}{l}\text { Mean difference } \\
\quad(95 \% \mathrm{Cl})\end{array}$} \\
\hline & \multicolumn{2}{|c|}{$\begin{array}{l}\text { Intervention } \\
n=253\end{array}$} & \multicolumn{2}{|c|}{$\begin{array}{l}\text { Control } \\
n=258\end{array}$} & \\
\hline & Before & After & Before & After & \\
\hline Total composite score $\dagger$ & $5.19(2.14)$ & $6.52(2.30)$ & $5.19(2.16)$ & $5.25(2.52)$ & $1.27(0.79$ to 1.75$) \dagger \dagger$ \\
\hline $\begin{array}{l}\text { Patients with improvement for total } \\
\text { composite score, no. }(\%)\end{array}$ & \multicolumn{2}{|c|}{$156(61.7)$} & \multicolumn{2}{|c|}{$110(42.6)$} & $19.1 \%+\dagger$ \\
\hline $\begin{array}{l}\text { Patients with improvement of } \geq 3 \text { points } \\
\text { on total composite score, no. (\%) }\end{array}$ & \multicolumn{2}{|c|}{$88(34.8)$} & \multicolumn{2}{|c|}{$46(17.8)$} & $17.0 \%+\dagger$ \\
\hline \multicolumn{6}{|l|}{ Process score } \\
\hline Glycated hemoglobin§ & $0.60(0.49)$ & $0.88(0.33)$ & $0.62(0.49)$ & $0.70(0.46)$ & 0.19 (0.09 to 0.29$)$ \\
\hline Blood pressure** & $1.03(0.79)$ & $1.52(0.68)$ & $1.12(0.77)$ & $1.27(0.74)$ & 0.34 (0.19 to 0.49$)$ \\
\hline LDL cholesterol§ & $0.49(0.50)$ & $0.78(0.42)$ & $0.45(0.50)$ & $0.56(0.50)$ & $0.18(0.07$ to 0.28$)$ \\
\hline Albuminuria§ & $0.29(0.46)$ & $0.70(0.46)$ & $0.30(0.46)$ & $0.43(0.50)$ & 0.27 (0.16 to 0.39$)$ \\
\hline $\mathrm{BMI} * *$ & $0.49(0.64)$ & $0.75(0.75)$ & $0.45(0.64)$ & $0.54(0.69)$ & $0.17(0.02$ to 0.32$)$ \\
\hline Foot surveillance§ & $0.28(0.45)$ & $0.51(0.50)$ & $0.28(0.45)$ & $0.36(0.48)$ & $0.16(0.06$ to 0.25$)$ \\
\hline Exercise** & $1.00(0.00)$ & $0.69(0.46)$ & $1.00(0.00)$ & $0.69(0.46)$ & $-0.01(-0.09$ to 0.07$)$ \\
\hline Smoking** & $1.00(0.06)$ & $0.69(0.46)$ & $0.97(0.17)$ & $0.69(0.46)$ & $-0.03(-0.12$ to 0.06$)$ \\
\hline ABC composite & $1.80(1.10)$ & $2.55(0.83)$ & $1.82(1.08)$ & $2.08(1.06)$ & $0.49(0.27$ to 0.70$)$ \\
\hline
\end{tabular}

Note: $A B C$ composite = composite of " $\mathrm{A}_{1 \mathrm{c}}$ " (glycated hemoglobin), blood pressure and $\mathrm{LDL}$ cholesterol; $\mathrm{BMI}=$ body mass index; $\mathrm{Cl}=\mathrm{confidence} \mathrm{interval;} \mathrm{LDL}=$ lowdensity lipoprotein; SD = standard deviation.

*Unless indicated otherwise.

tMaximum $=10$.

¥Range: -2 to +2 .

$\S$ Measured semiannually.

$* *$ Measured quarterly.

$\dagger+p<0.001$. 
pressure $(-3.95 \mathrm{~mm} \mathrm{Hg}$ systolic blood pressure, 95\% CI -7.64 to $-0.26, p=0.036 ;-2.38 \mathrm{~mm} \mathrm{Hg}$ diastolic blood pressure, $95 \% \mathrm{CI}-4.60$ to $0.17, p=0.035)$ and in glycated hemoglobin $(-0.20 \%, 95 \% \mathrm{CI}-0.38 \%$ to $-0.02 \%, p=0.029)$.

\section{Other outcomes}

By the end of the study, patients in the intervention group were more optimistic than those in the control group in terms of their daily productivity and ease of management of their diabetes, their relationship with their respective primary care providers and the quality of their diabetes care. One hundred and ninety-two $(75.9 \%)$ of the intervention patients were as satisfied or more satisfied with their care since starting to use the tracker system. There were no statistically significant changes in quality-of-life measures (SF-12 and Diabetes-39) or continuity of care, ${ }^{33}$ despite positive trends.

Table 4: Results for clinical outcomes

\begin{tabular}{|c|c|c|c|c|c|c|c|c|c|}
\hline \multirow[b]{3}{*}{ Outcome } & \multicolumn{4}{|c|}{ Intervention } & \multicolumn{4}{|c|}{ Control } & \multirow{3}{*}{$\begin{array}{l}\text { Difference between } \\
\text { groups* }(95 \% \mathrm{Cl})\end{array}$} \\
\hline & \multicolumn{2}{|r|}{ Before } & \multicolumn{2}{|r|}{ After } & \multicolumn{2}{|r|}{ Before } & \multicolumn{2}{|r|}{ After } & \\
\hline & $n$ & Mean (SD) & $n$ & Mean (SD) & $n$ & Mean (SD) & $n$ & Mean (SD) & \\
\hline \multicolumn{10}{|l|}{ Clinical variables } \\
\hline $\begin{array}{l}\text { Systolic blood pressure, } \\
\mathrm{mm} \mathrm{Hg}\end{array}$ & 178 & $135.2(17.6)$ & 226 & $130.5(16.4)$ & 195 & $134.8(18.4)$ & 213 & $135.1(18.4)$ & $-3.95(-7.64 \text { to }-0.26)^{* *}$ \\
\hline $\begin{array}{l}\text { Diastolic blood } \\
\text { pressure, mm Hg }\end{array}$ & 178 & $76.1(11.1)$ & 226 & $73.6(9.9)$ & 195 & $74.7(10.3)$ & 213 & $75.4(10.5)$ & $-2.38(-4.60$ to 0.17$) \dagger \dagger$ \\
\hline $\begin{array}{l}\text { LDL cholesterol, } \\
\mathrm{mmol} / \mathrm{L}\end{array}$ & 124 & $2.41(0.65)$ & 197 & $2.43(0.78)$ & 115 & $2.59(0.87)$ & 144 & $2.54(0.81)$ & $-0.002(-0.14$ to 0.14$)$ \\
\hline Glycated hemoglobin, \% & 153 & $7.0(1.4)$ & 222 & $6.8(1.2)$ & 159 & $7.1(1.6)$ & 180 & $7.3(1.6)$ & $-0.20(-0.38$ to -0.02$) \neq \ddagger$ \\
\hline Albuminuria, mg/mol & 63 & $5.80(15.0)$ & 171 & $6.89(17.9)$ & 67 & $5.13(13.2)$ & 101 & $5.95(15.6)$ & 0.65 (-1.11 to 2.41$)$ \\
\hline BMI & 101 & $32.1(8.2)$ & 140 & $31.6(7.5)$ & 92 & $31.6(6.9)$ & 108 & $31.9(7.0)$ & $0.02(-1.24$ to 1.28$)$ \\
\hline $\begin{array}{l}\text { Exercise, } \mathrm{min} / \mathrm{wk} \text {, } \\
\text { median (IQR) }\end{array}$ & 170 & $60.0(180.0)$ & 170 & $127.5(230.0$ & 178 & $90.0(150.0)$ & 178 & $122.5(240.0)$ & $5.18(-43.50$ to 53.86$)$ \\
\hline Feet, no neuropathy & 70 & $0.94(0.23)$ & 128 & $0.92(0.27)$ & 72 & $0.96(0.20)$ & 91 & $0.90(0.30)$ & $0.01(-0.08$ to 0.10$)$ \\
\hline Nonsmoker & 252 & $0.88(0.33)$ & 175 & $0.87(0.33)$ & 250 & $0.84(0.37)$ & 179 & $0.85(0.36)$ & $-0.02(-0.09$ to 0.04$)$ \\
\hline \multicolumn{10}{|c|}{ Clinical composite score } \\
\hline Change in scoret‡ & & & 238 & $0.33(1.64)$ & & & 241 & $-0.16(1.48)$ & $0.55(0.04 \text { to } 1.07)^{* *}$ \\
\hline $\begin{array}{l}\text { Change in } A B C \\
\text { composite score } \neq\end{array}$ & & & 201 & $0.01(1.41)$ & & & 193 & $-0.39(1.26)$ & $0.34 \quad(0.04$ to 0.65$) \S \S$ \\
\hline $\begin{array}{l}\text { No. of variables on } \\
\text { target§ }\end{array}$ & 253 & $2.51(1.44)$ & 252 & $3.33(1.66)$ & 258 & $2.34(1.45)$ & 248 & $2.49(1.56)$ & $0.16(-0.12$ to 0.44$)$ \\
\hline $\begin{array}{l}\text { No. of } A B C \text { variables } \\
\text { on target }\end{array}$ & 211 & $0.99(0.81)$ & 241 & $1.44(0.86)$ & 218 & $0.96(0.88)$ & 227 & $1.02(0.92)$ & $0.19(0.004 \text { to } 0.38)^{* * *}$ \\
\hline \multicolumn{10}{|l|}{$\begin{array}{l}\text { On-target for clinical } \\
\text { variables }\end{array}$} \\
\hline Systolic blood pressure & 178 & $0.31(0.47)$ & 226 & $0.45(0.50)$ & 195 & $0.34(0.47)$ & 213 & $0.34(0.48)$ & \multirow{2}{*}{$0.13 \quad(0.02$ to 0.25$)+t \dagger$} \\
\hline Diastolic blood pressure & 178 & $0.53(0.50)$ & 226 & $0.69(0.47)$ & 195 & $0.57(0.50)$ & 213 & $0.56(0.50)$ & \\
\hline LDL cholesterol & 124 & $0.66(0.48)$ & 197 & $0.61(0.49)$ & 115 & $0.57(0.50)$ & 144 & $0.60(0.49)$ & $-0.02(-0.14$ to 0.10$)$ \\
\hline Glycated hemoglobin & 153 & $0.56(0.50)$ & 222 & $0.63(0.48)$ & 159 & $0.57(0.50)$ & 180 & $0.51(0.50)$ & 0.08 (-0.01 to 0.17$)$ \\
\hline Albuminuria & 63 & $0.83(0.38)$ & 171 & $0.71(0.45)$ & 67 & $0.64(0.48)$ & 101 & $0.69(0.46)$ & $-0.01 \quad(-0.11$ to 0.09$)$ \\
\hline BMI & 101 & $0.30(0.46)$ & 140 & $0.26(0.44)$ & 92 & $0.28(0.45)$ & 108 & $0.23(0.42)$ & $-0.001(-0.11$ to 0.11$)$ \\
\hline Exercise & 253 & $0.22(0.42)$ & 170 & $0.36(0.48)$ & 258 & $0.18(0.39)$ & 178 & $0.32(0.47)$ & $-0.01 \quad(-0.10$ to 0.08$)$ \\
\hline Feet, no neuropathy & 70 & $0.94(0.23)$ & 128 & $0.92(0.27)$ & 72 & $0.96(0.20)$ & 91 & $0.90(0.30)$ & $0.01(-0.08$ to 0.10$)$ \\
\hline Nonsmoker & 252 & $0.88(0.33)$ & 175 & $0.87(0.33)$ & 250 & $0.84(0.37)$ & 179 & $0.85(0.36)$ & $-0.02(-0.09$ to 0.04$)$ \\
\hline
\end{tabular}

Note: $\mathrm{ABC}$ composite = composite of " $\mathrm{A}_{1 \mathrm{c}}$ " (glycated hemoglobin), blood pressure and $\mathrm{LDL}$ cholesterol; $\mathrm{BMI}=$ body mass index; $\mathrm{Cl}=$ confidence interval; $\mathrm{IQR}=$ interquartile range; $L D L=$ low-density lipoprotein; $S D=$ standard deviation.

*Differences are based on multiple imputation (may differ slightly from raw results).

tPotential range for change in clinical composite score: -8 to +8 .

fFor these 2 rows, data represent the change for each group over the study period (difference between "before" and "after").

$\S$ Range of scores for on-target clinical composite: 0 to 8 (blood pressure counted as 1 variable).

$* * p=0.036$.

$\dagger+* * p=0.049$

$\ddagger \neq p=0.029$.

$\S \S p=0.028$.

$* * * p=0.049$.

†††Both systolic and diastolic blood pressure had to be on target. 
In providing their feedback, many primary care providers noted that the technical difficulties with the electronic decisionsupport tool had a negative effect on the perceived usefulness of the intervention. Despite this reservation, $48 \%$ (16/33) felt that their knowledge of diabetes targets had improved, $33 \%$ (11/33) felt that patients' adherence with appointments had improved, and 36\% (12/33) felt that patients' access to high-quality diabetes care had improved (as opposed to no change).

Both patients and providers identified the main technical difficulty as lack of reliable access to the Web-based version of the diabetes tracker, which was attributed to suboptimal provincial health infrastructure. In addition, the inability to completely integrate the tracker's decision-support system with each of the 5 different types of electronic medical records, which would have allowed automated updating between the patient's medical record and the tracker system, meant that monitoring data had to be entered twice to keep both systems current. Lower-priority items mentioned by participants included the need for passwords, which were frequently misplaced by patients, and the feeling that nightly updating of intervention patients' tracker variables was not sufficiently timely.

\section{Interpretation}

E-health trials and their intervention arms represent a complex form of research - complex to develop, to implement and to evaluate. ${ }^{34}$ Despite the technical challenges for both patients and primary care providers in this study, we have demonstrated that the care of a complex chronic disease can be improved with electronic tracking and decision support shared by providers and patients. Unlike the current trial, previous trials have been conducted in institutional settings, where information technology support is continuously and readily available, and have involved in-house electronic decision-support systems typically developed often over a period of decades ${ }^{35}$ Key elements of our intervention included its simultaneous focus on both providers and patients, multiple communication approaches (electronic, telephone and paper) and point-of-care multifactorial computerized monitoring and decision support.

However, the changes in outcomes that we observed were modest, as has been found in other interventions for the management of chronic disease. Several explanations are plausible. First, management of complex chronic diseases is especially difficult in the community, where the intense and frequent reminders, follow-up and support that may be required for important change are not generally available. Second, trials such as these frequently require pretesting and refinement to prepare the research setting, intervention, methods and outcomes of interest. ${ }^{35}$ Third, we and others have found that computerized decision-support interventions, even those limited to prescribing, vary greatly in their characteristics or features. ${ }^{36}$ Without better descriptions, it has been impossible to evaluate which features predict success and which predict failure, so that the effectiveness of the intervention can be improved. Fourth, the technical issues preventing instant access to necessary monitoring and advice are an underrecognized source of failure of computerized decision-support systems. Canadian e-health regulators and payers do not require stan- dards for data extraction from the country's multiple electronic medical records; this lack of standards has led to expensive integration challenges and has inhibited rapid access to data by providers and patients. In addition, the failure by health jurisdictions to provide fast, reliable and secure Internet communication is a fundamental barrier to e-health progress.

The limitations of our research also include the relatively short follow-up time (6 months) and the resultant use of surrogate outcomes. For example, although process outcomes are often used for short-term trials, the optimal timing of process (checking a vascular risk factor, for example) has not been rigorously studied. ${ }^{37}$ In addition, short-term follow-up led to a paradoxical situation in which the process improved markedly, only to reduce or minimally improve the overall mean score for clinical targets. Some of this is likely the result of newly identifying patients with poorer control, a worthwhile outcome in itself. Finally, although use of an intervention that targets multiple risk factors has been shown to significantly reduce vascular, renal, eye and neuropathy events, ${ }^{8}$ it is not clear which of the clinical markers it is most important to target through behavioural or medication interventions.

Although we have demonstrated that individualized, evidence-based computerized decision support holds some promise for improving clinical care, there is as yet no compelling evidence of an important effect on major patient morbidity (e.g., cardiovascular and renal events). Providers who are not participating in research on these systems are correct to proceed cautiously and to be skeptical of current claims of improved efficiency, in terms of both time and money. The policy implications of this research are more immediate. There is an urgent need to improve the management of chronic diseases such as diabetes, and there is evidence that small changes in each of several risk factors can cumulatively have major clinical impact. Multiple types of electronic assistance, from simple archiving of the information in patient charts to the provision of specific, individual, real-time advice, have been proposed. Very little research on these topics exists in Canada, despite millions of patients with diabetes, vascular disease and other chronic diseases. We urgently require that the degree of policy rigour that has been applied to drugs be applied to broader e-health interventions for the management of chronic disease, to understand where electronic decision support is most likely to be cost-effective. A cost-effectiveness analysis of this trial is now under way.

This article has been peer reviewed.

Competing interests: None declared.

Contributors: Anne Holbrook was responsible for the conception and design of the study, the peer-reviewed process for seeking funding, the interpretation of the data, the writing of the manuscript and manuscript revisions. Lehana Thabane made significant contributions to interpretatton of the data and also took part in editing the manuscript. Karim Keshavjee led the design of the intervention, assisted with project management and assisted in editing the manuscript. Lisa Dolovich, Bob Bernstein and David Chan are clinical primary care leaders who assisted with study design, recruitment of patients, project management and editing of the manuscript. As the project research coordinator, Sue Troyan assisted with data collection and also assisted in managing the manuscript revisions. Gary Foster was responsible for analyzing the data. He also took part in interpreting and verifying the data. Hertzel Gerstein acted as the resource person for the diabetes evidence, assisted with 
interpretation of the data and helped in editing the manuscript. All of the authors approved the final version of the paper submitted for publication.

Funding: This study was funded by a grant from the Canada Health Infostructure Partnerships Program Project 35b, Health Canada.

\section{REFERENCES}

1. National diabetes statistics 2007. Bethesda (MD): National Diabetes Information Clearinghouse; 2008. Available: http://diabetes.niddk.nih.gov/dm/pubs/statistics /\#14 (accessed 2009 Jan. 21).

2. The prevalence and costs of diabetes. Toronto $(\mathrm{ON})$ : Canadian Diabetes Association. Available: www.diabetes.ca/about-diabetes/what/prevalence/ (accessed 2009 Jan. 21).

3. American Diabetes Association. Standards of medical care in diabetes - 2007 . Diabetes Care 2007;30(Suppl 1):S4-41.

4. UK Prospective Diabetes Study Group. Intensive blood-glucose control with sulphonylureas or insulin compared with conventional treatment and risk of complications in patients with type 2 diabetes (UKPDS 33) [published erratum in Lancet 1999;354:602]. Lancet 1998;352:837-53.

5. UK Prospective Diabetes Study Group. Tight blood pressure control and risk of macrovascular and microvascular complications in type 2 diabetes: UKPDS 38 [published erratum in BMJ 1999;318:29]. BMJ 1998;317:703-13.

6. Collins R, Armitage J, Parish S, et al.; Heart Protection Study Collaborative Group. MRC/BHF heart protection study of cholesterol-lowering with simvastatin in 5963 people with diabetes: a randomised placebo-controlled trial. Lancet 2003:361:2005-16

7. Canadian Diabetes Association. 2003 clinical practice guidelines. Toronto (ON): The Association; 2003. Available: www.diabetes.ca/cpg2003/ (accessed 2009 Jan. 21).

8. Gaede P, Lund-Andersen $\mathrm{H}$, Parving $\mathrm{HH}$, et al. Effect of a multifactorial intervention on mortality in type 2 diabetes. N Engl J Med 2008;358:580-91.

9. Saydah SH, Fradkin J, Cowie CC. Poor control of risk factors for vascular disease among adults with previously diagnosed diabetes. JAMA 2004;291:335-42.

10. Brown LC, Johnson JA, Majumdar SR, et al. Evidence of suboptimal managemen of cardiovascular risk in patients with type 2 diabetes mellitus and symptomatic atherosclerosis. CMAJ 2004;171:1189-92.

11. Chodosh J, Morton SC, Mojica W, et al. Meta-analysis: chronic disease selfmanagement programs for older adults. Ann Intern Med 2005;143:427-38.

12. Ellis SE, Speroff T, Dittus RS, et al. Diabetes patient education: a meta-analysis and meta-regression. Patient Educ Couns 2004;52:97-105.

13. Norris SL, Nichols PJ, Caspersen CJ, et al. Increasing diabetes self-management education in community settings. A systematic review. Am J Prev Med 2002;22(4 Suppl):39-66.

14. Renders CM, Valk GD, Griffin S, et al. Interventions to improve the management of diabetes mellitus in primary care, outpatient and community settings. Cochrane Database Syst Rev 2001;(1):CD001481

15. van Dam HA, van der Horst F, van den Borne B, et al. Provider-patient interaction in diabetes care: effects on patient self-care and outcomes. A systematic review. Patient Educ Couns 2003;51:17-28.

16. Branger PJ, van't Hooft A, van der Wouden JC, et al. Shared care for diabetes supporting communication between primary and secondary care. Int J Med Inform 1999;53:133-42.

17. Smith S, Bury G, O'Leary M, et al. The North Dublin randomized controlled trial of structured diabetes shared care. Fam Pract 2004;21:39-45.

18. Smith SM, Allwright S, O'Dowd T. Effectiveness of shared care across the interface between primary and specialty care in chronic disease management. Cochrane Database Syst Rev 2007;(3):CD004910.
19. Davis K, Schoen C, Schoenbaum SC, et al Mirror, mirror on the wall: an international update on the comparative performance of American health care. New York (NY): The Commonwealth Fund; 2007. Available: www.commonwealthfun org/publications/publications show.htm?doc id=482678 (accessed 2009 Apr. 24).

20. Keshavjee K. EMR implementation in Ontario. Position paper to increase the deployment of electronic medical records in Ontario. Toronto $(\mathrm{ON})$ : InfoClin Inc.; 2007. Available: http://blog.canadianemr.ca/Articles/Intel_InfoClin_EMR_White Paper_Final_080125.pdf (accessed 2009 Apr. 24).

21. Balas EA, Krishna S, Kretschmer RA, et al. Computerized knowledge management in diabetes care. Med Care 2004;42:610-21.

22. Griffin S, Kinmonth AL. Diabetes care: the effectiveness of systems for routine surveillance for people with diabetes. Cochrane Database Syst Rev 2000;(2): CD000541.

23. Garg AX, Adhikari NK, McDonald H, et al. Effects of computerized clinical decision support systems on practitioner performance and patient outcomes: a systematic review. JAMA 2005;293:1223-38.

24. Expert Committee on the Diagnosis and Clasification of Diabetes Mellitus. American Diabetes Association: clinical practice recommendations 2002. Diabetes Care 2002;25 Suppl 1:S1-S147.

25. COMPETE II extended core dataset. Hamilton $(\mathrm{ON})$ : Centre for the Evaluation of Medicines; 2002. Available: www.compete-study.com/C2_dataset.htm (accessed 2009 Jan. 21)

26. Dolovich LR, Nair KM, Ciliska DK, et al. The Diabetes Continuity of Care Scale: the development and initial evaluation of a questionnaire that measures continuity of care from the patient perspective. Health Soc Care Community 2004;12:475-87.

27. Ware JE, Kosiniski M, Turner-Bowker DM, et al. How to score version 2 of the SF-12 Health Survey (with a suppliment documenting version 1). Lincoln (RI) Quality Metric Incorporated; 2002.

28. Boyer JG, Earp JA. The development of an instrument for assessing the quality of life of people with diabetes. Diabetes-39. Med Care 1997;35:440-53.

29. Garratt AM, Schmidt L, Fitzpatrick R. Patient-assessed health outcome measures for diabetes: a structured review. Diabet Med 2002;19:1-11.

30. Mollon B, Holbrook AM, Keshavjee K, et al. Automated telephone reminder messages can assist electronic diabetes care. J Telemed Telecare 2008;14:32-6.

31. Little RJA, Rubin DB. Bayes and multiple imputation. In: Statistical analysis with missing data. 2nd ed. New York (NY): Wiley; 2002. p. 200-2.

32. Perera R, Heneghan C, Yudkin P. Graphical method for depicting randomised trials of complex interventions. BMJ 2007;334:127-9.

33. Nair KM, Dolovich LR, Ciliska DK, et al. The perception of continuity of care from the perspective of patients with diabetes. Fam Med 2005;37:118-24

34. Shcherbatykh I, Holbrook A, Thabane L, et al. Methodologic issues in health informatics trials: the complexities of complex interventions. J Am Med Inform Assoc 2008; $15: 575-80$.

35. Chaudhry B, Wang J, Wu SY, et al. Systematic review: impact of health information technology on quality, efficiency, and costs of medical care. Ann Intern Med 2006; $144: 742-52$

36. Mollon B, Chong J, Holbrook A, et al. Factors determining the success of computerized decision support in prescribing: a systematic review. Can J Clin Pharmaco 2007; 14:e130

37. Bowker SL, Majumdar SR, Johnson JA. Systematic review of indicators and measurements used in controlled studies of quality improvement for type 2 diabetes. Can J Diabetes 2005;29:230-8.

Correspondence to: Dr. Anne Holbrook, clo Centre for Evaluation of Medicines, McMaster University, 105 Main St. E, P1 level, Hamilton ON L8N 1G6; fax 905 528-7386; holbrook@mcmaster.ca 